Edutaining audio: an exploration of education podcast design possibilities

Christopher Drew

School of Social Sciences and Law, Teesside University, Middlesbrough, United Kingdom

c.drew@tees.ac.uk 


\section{Edutaining audio: an exploration of education podcast design}

\section{possibilities}

The versatility, intimacy, and ease of production of podcasting makes it a logical technology to apply to flexible education contexts. As a result, there has been increasing scholarly interest in the value of education podcasting in recent years. While education podcasting literature has tended to explore podcast implementation in institutional contexts, education podcasts outside of academia have also grown in popularity, to the extent that 'education' is a common sub-group in podcast aggregation sites. This paper adapts Fernandez, Sallan and Simo's (2015) framework of variables in education podcast design, to conduct a textual analysis of emergent design themes in non-institutional education podcasts. The findings reveal how highly successful podcasts from outside of educational institutions can both reinforce and challenge norms about education podcast design that exist within academic discourse, including in regards to podcast length, pedagogical approaches, and the position of the podcast in the learning experience. It is the hope that the findings of this study might shift discourse from an interest in universalizing ideas about 'good practice' in education podcast design, towards more nuanced discussion of design practices that fit within specific contexts.

Keywords: education podcasting; podcast; Web 2.0 design

\section{Introduction}

A podcast is an audio recording that can be delivered directly to consumers' media devices, including portable music players, computers, laptops, and smartphones (Kidd, 2011).

Podcasts emerged in the early 2000s during the boom of Web 2.0 technologies, and were quickly adopted by educators who saw potential benefits of the medium. In the intervening time, scholars have grappled with the potential of podcasting for education. One of the key concerns within academic literature about podcasting in education is over how podcasts can best be designed to enhance students' learning experiences. Many (Fernandez, Sallan, \& Simo, 2015; Hew \& Cheung 2013; Abdous, Facer, \& Yen 2012) are concerned that podcasts tend to be designed in rather regressive ways, such as through simply recording lecture 
proceedings or providing pre-exam content review, rather than being designed for unique learning opportunities. As Lonn and Teasley (2009, p. 91) state,

before any real value for learning can be demonstrated with this technology, the research on educational use of podcasting needs to address the conceptual issue of whether this technology is simply a mechanism for student review or a valuable method for students to construct knowledge

What Lonn and Teasley (2009) allude to, is a lack of certainty about the possibilities of podcasting in education. This paper has as its starting point a concern over such possibilities, and how they can be realized through podcast design. It examines a small corpus of education podcasts from non-institutional contexts, to identify a range of possible designs that could be applied to both non-institutional and institutional education podcasts. These non-institutional education podcasts, designed by entrepreneurs of the medium and uploaded to podcast aggregation sites like iTunes and Juice, can not only provide insights into the ways podcasts can be variously used for education, but also both reinforce and challenge extant norms in the literature about good practice in education podcast design.

The paper opens with a discussion of previous literature on podcasting in education, and reviews current discourse around good practice in podcast design. It then introduces Fernandez et al.'s (2015) framework for examining variables in podcast design which is used in the study. The most salient findings from the study are then presented, including findings which both affirm and contradict orthodox design ideals in extant literature. The paper concludes with a discussion of the relevance of the findings, and an outline of potential lines for future research into education podcast design.

\section{The potential value of podcasting in education}

Unlike radio broadcasts, which have been in existence for several decades for correspondence learners (Lee \& Tynan, 2008), podcasts are unique for their availability online, ease of 
production, staggered release and playability at any time. As downloadable content, students can carry podcasts on portable devices and listen to them in places that suit them, such as on busses, in the car and while exercising, making them a valuable affordance for blended and distance learning. For teachers, podcasts are cheap to produce, requiring little more than simple recording software and a microphone. They are also easy to distribute thanks to sites like iTunes and Podbay, making radio-style broadcast possible for educators around the world. It is little wonder, then, that podcast usage in education institutions has steadily grown since the emergence of the medium in the early 2000 s.

Scholarly attention to education podcasting has paralleled the growth of usage. Scholars - commonly through action research projects - have enthusiastically studied ways in which podcasting might add value to learning. While research exists into various podcast uses, including their use in K-12 settings and the notion of student-created podcasts, the majority of scholarly interest in the topic has been concerned with the value of teachercreated podcasts in tertiary education settings. Amongst these studies, scholars have seen the possibilities of teacher-produced podcasts to enrich online learning modules that had hitherto been dominantly text-based (Fothergill, 2008; On Tam, 2012), as well as for on-campus education where a podcast is often seen as an alternative to lectures (Hew \& Cheung, 2013; Hadjianastasis \& Nightingale, 2016).

There has been particular interest in potential value of teacher-created podcasts for distance mode students. An oft cited rationale for the use of podcasts in distance mode courses is the enhanced sense of community amongst learners, whereby hearing the inflections of a human voice in an online course has the capacity to minimize the sense of isolation when learning online (Nie, Armellini, Harrington, Barklamb, \& Randall, 2010; Lee \& Tynan 2008; Lee \& Chan, 2007). Podcasting can furthermore build rapport between 
teacher and learner, and have the flow on effect of enhancing students' motivation to engage with online forums (Lee \& Chan, 2007).

Benefits for on-campus students significantly differ; and indeed, debate continues as to whether benefits outweigh potential pitfalls. Scholars have been concerned over whether students will attend lectures if lecture review podcasts are provided. While some have noted significant drops in in-class attendance (Fernandez, 2007), others have not (Larkin, 2010; Lonn \& Teasley, 2009). Additionally, while one of the key affordances of podcasting is that it allows learning to take place in a student's own time, it has been found that listening to podcasts will often be delayed until shortly before pressing submission dates (Lonn \& Teasley, 2009). Results on the effectiveness of podcasts for improving grades also remain inconclusive (Abdous et al., 2012).

The mixed results of podcast efficacy have erstwhile been attributed to difference in design features of education podcasts across various studies (Fernandez et al, 2015). Resultantly, discussion has pivoted recently towards exploration of considerations for podcast design, to explore how to maximise the perceived benefits of podcasting for education (Seery, 2012; Abdous et al., 2012; Kidd 2011). The next section outlines some common design features of education podcasting, as well as aspects that are often cited as desirable in podcast design.

\section{Education podcast design considerations}

Teacher-created podcasts have variously been designed to make lecture recordings available to students; provide content review prior to exams; provide feedback to students; distribute administrative information; disseminate interviews with practitioners; and function as unique lessons by introducing new content to the course. These uses are commonly divided into three categories: 'substitutional' (Seery, 2012) podcasts which involve recordings of in-class 
content, nonessential 'supplemental' podcasts which provide review of in-class content; and 'integrated' podcasts which provide unique content such as guest interviews, podcast-only lessons, and roundtable discussions (Abdous et al., 2012). Several studies (Hew, 2009; Abdous et al., 2012; Hew \& Cheung 2013) have found that integration of podcasts is significantly rarer than substitutional and supplemental podcasts, indicating that podcasting tends not to be seen as 'a new tool offering opportunities to build new knowledge' (Fernandez et al., 2015, p. 311) but rather an addendum to extant coursework.

In attempting to disseminate knowledge about podcast design, particularly in relation to the rarer form of 'integrated' unique content podcasts, many scholars have highlighted various 'tips' at the end of their studies, that highlight good practice (On Tam, 2012; Kidd, 2011; Seery, 2012). Kidd (2011), for example, highlights the importance of using signposting techniques when recording podcasts. He highlights the need for signposting to 'locate the audience within the audio' (p. 55; see also Seery, 2012) so as to sustain listener attention. Signposts fit both at the beginning and end as bookends to the podcast, but also throughout where 'counting and summarising points' (Kidd, 2011, p. 55) can provide clarity for learners.

Kidd's (2011) outline of good practices also highlights the need for brevity, a point that enjoys broad support in the literature. Commonly cited is Walsh (2004), who argues that a podcast should be comparable in length to a song. Downbeat segments lose the attention of students very quickly, leading for the need to "tell it quick and tell it straight" (Walsh, 2004, p. 24). Sentiments towards brevity have also been backed by Chan and Lee (2005), whose argument for shorter podcasts is that they should be able to fit within transit time of students as they walk between lecture halls or travel to and from university. Perhaps more compelling is On Tam's (2012) research, in which he surveys students' reactions to the rollout of podcasts in a university unit. $85.5 \%$ of students reported that they most valued podcasts shorter than 15 minutes long. 
Others have highlighted the importance of creating a degree of informality in podcasts in order to sustain the interest of listeners (Fothergill, 2008; Salmon \& Nie, 2008). Given voice is so central to the podcast experience, scholars are quick to want to 'inject personality' (Bell, Cockburn, Wingkvist, and Green, 2007, p. 8) into podcasts and avoid monotony. Incorporation of jokes, back-and-forth chat, and broken-up broadcast segments (Fothergill, 2008) have all been cited as effective ways of maintaining listener attention. This was particularly emphasised by the scholars from the influential IMPALA study into podcasting, whose student feedback results highlight that 'a friendly and informal tone appeals to students' (Salmon \& Nie, 2008, p. 8) and keeps them 'listening to the end' (Fothergill, 2008, p. 88).

\section{Framework for the analysis of education podcast designs}

The above elements of podcast design have been evident in several frameworks for exploring podcast design features (Rosell-Aguilar, 2007; Carvalho, Aguilar, Carvalho, \& Cabecinhas, 2009; Fernandez et al., 2015). This paper's study of the design features of 20 top rated education podcasts has found particular value in Fernandez et al.'s (2015, p. 307) 'guidelines for the study of podcasting', which present arguably the most extensive framework for examining a breadth of variables in podcast design. This framework has been suggested as a way of enhancing credibility and transferability to studies of podcast design by providing a transparent and structured way of accounting for a breadth of design variables. Fernandez et al.'s (2015) framework is initially based on five design variables described by Carvalho et al. (2009):

(1) Type of content. Podcasts tend to fall into several content type categories including lecture recordings; review material; assessment feedback; administrative information; unique learning materials; and interviews of experts. 
(2) Length. Carvalho et al. (2009) dissect podcast length into three categories: short (1-5 minutes) medium (5-15 minutes) and long (15+ minutes)

(3) Author. The author is usually a teacher, student, guest, or a combination.

(4) Style. Formal podcasts are direct and often read from a script, while informal podcasts can often involve improvisation, humour, and entertainment segments.

(5) Purpose. Carvalho et al. (2009) suggest describing a podcast's purpose as a verb: inform, reflect, motivate, etc. Ferndandez et al. (2015) rephrase this category to ‘course objectives' and borrow cognitive verbs from Bloom's taxonomy. Such actions range from lower-order cognitive skills like knowledge and comprehension, through to mid-range skills of application and analysis, and higher level cognitive functions of synthesis and evaluation (Fernandez et al., 2015).

Building on Carvalho et al.'s (2009) work, Fernandez et al. (2015, p. 307) add several factors:

(6) Voice / Mode of Address. Pace and intonation of voice can contribute to the overall quality of the podcast. Fernandez et al. (2015) encourage researchers to consider how engaging and clear the voice is for the listener. I have expanded the concern over voice in this study to also consider the subjects to which the voice speaks. Some podcasts address listeners directly, others engage in storytelling (Lindgren, 2016), and others involve multi-presenter cross-talk for consumers to ‘listen in’ (Ames, 2016).

(7) Fit with other materials. Several scholars (Lonn \& Teasley, 2009; Abdous et al., 2012) emphasise the need for podcasts to integrate with other learning materials in the unit of work rather than to function as an addendum to extant course materials. Study of fit with other materials examines the extent to which a podcast will 'synergize with other elements' (Fernandez et al., 2015, p. 318) within the course, such as associated worksheets and face-to-face lessons. 
In extending Fernandez et al.'s (2015, p. 318) 'fit with other learning materials' criterion, this study has also added the criterion of 'series structure' in order to identify a podcast's fit not only with other materials, but also other podcasts within the podcast series:

(8) Series structure. Podcasts have the affordance of being released in a series, whereby new podcasts are 'pushed' through Really Simple Syndications (RSS) feeds to students' media devices upon release. The relationships between podcasts in series can vary. Series can progress in a linear structure wherein content in each podcast builds upon the previous either through progression in coursework or a progressing narrative. Series can also be non-linear whereby each podcast's content is based around factors such as listener requests and current affairs.

Furthermore, I have found Bower et al (2010)'s explorations of pedagogies in Web 2.0 design and Rosell-Aguilar's (2007) arguments for the need to consider pedagogical approaches in education podcast design sufficiently compelling to include as a variable in this study:

(9) Pedagogical approach. Bower, Hedberg and Kuswara (2010) highlight four key pedagogical approaches to consider in Web 2.0 design. These include transmissive pedagogy, 'where a stream of information is broadcast to learners' (Bower et al., 2010, p. 182) such as in a lecture-style podcast; dialogic pedagogy involving multiple points of views for critical analysis, such as in roundtable podcast discussions; constructionist pedagogy; and co-constructive pedagogy where 'groups of learners complete a series of goal-related tasks' (p. 182). While constructivist pedagogy might be seen as incompatible with pre-recorded podcasts, a Piagetian approach to constructivism highlights that two-way interaction 'is not necessary and learners can learn from noninteractional input, which supports the use of podcasting within [a constructivist] framework' (Rosell-Aguilar, 2007, p. 477). In the case of co-constructive learning, a 
podcast cannot involve immediate communication between learners; however, it can lead to subsequent interactional activities such as forum tasks that enable coconstruction of knowledge.

Lastly, this study included 'subject' as a key factor to consider, to further understand the relationship between subject matter and podcast design:

(10) Subject. Four subject areas have been identified across the corpus of podcasts in this study: history, languages, sciences, and psychology.

Some factors in Fernandez et al.'s (2015) framework are not present in this study, including 'medium', which they use when examining of both audio-only podcasts and video-based vodcasts. Vodcasts did not fit within the scope of this study, and therefore the 'medium' variable was not included. They also present 'distribution factors' as a variable, which was excluded given that a criterion for inclusion of podcasts in this study was that they were all distributed on publicly available podcast aggregation sites.

With this framework for analysis in place, a corpus of podcasts was gleaned from the podcast aggregation sites iTunes, Podbay and Juice, which all contained 'education' subcategories and popularity (by download) sort options. An initial corpus of 48 popular education podcasts collected from the top podcasts on each site was cross-checked against the Podcast Awards (www.podcastawards.com) list in the Education category, and podcasts that frequently emerged across multiple source lists were selected for the final corpus of 20 podcasts. During coding, the first three episodes of each series was listened to, as well as another five randomly selected episodes from each. Further episodes of importance were also listened to, such as special viewers' choice episodes from The History Chicks and the special 'telenovela' (sitcom) podcasts from Show Time Spanish, to gain a greater appreciation of the 
full range of products made available by each podcast series. The results of the analysis are summarised in Table 1.

[Table 1 near here - see appendix]

\section{Findings}

Perhaps one of the more interesting aspects of this study, is that the podcasts explored here are the central tools in the learning process, which enables practitioners to explore design features of podcasts that are unequivocally 'integrated' (Abdous et al., 2012) unique content podcasts, rather than substitutional or supplemental texts. It is possible that the centrality of these podcasts in the learning process has led to the significant divergences between the podcast designs in this study and conventional design ideals emerging from academia. In the interest of brevity, the following are five themes that emerged as the most prominent and consequential results from the study, focussing on those aspects that challenge or reaffirm the extant literature. Variables that were not included in the five key themes are nonetheless weaved through the discussion where relevant.

\section{Length}

Length of podcast emerges as one of the most salient aspects that makes these podcasts stand out from the conventional wisdom in the literature. A minority of podcasts ( 2 out of 20 ) in the study ran for less than 15 minutes. These podcasts both involved regular releases of new content and did not involve linear course content but new short bursts of information in each release. Of note, however, is that the shorter podcasts also aimed at the basic pedagogical level of data transmission, and the lower-level cognitive skill on Bloom's taxonomy of 'knowledge' given that they did not have the time to delve into analytical work. Academic consensus on brevity in podcasting (Kidd, 2011) may be of value for delivering snippets of 
information to learners, then, but short podcasts can fail to encourage students to engage in the higher order thinking necessary in tertiary education contexts.

On the other hand, 15 of the 20 podcasts examined had lengths significantly beyond 30 minutes, defying conventional wisdom that podcasts should be short and direct. History themed podcasts that engaged in storytelling (Hardcore History, Revolutions, History Chicks, British History Podcast) were the longest-running of the podcasts. Episodes ran for up to 3 hours in the case of Hardcore History. Science themed podcasts with panels of hosts (Probably Science, Star Talk, Science Friday, The Naked Scientists, You are not so Smart) also extended well beyond conventialised timeframes. In these podcasts, extensive cross-talk and analysis took place and time frames typically sat in the range of $30-60$ minutes. Of note is that such long-form podcasts have engaged online audiences sufficient to enable them to rise to the top of download charts on podcast aggregation sites; and therefore, the notion that long podcasts should be avoided, is undermined by the corpus examined in this study.

\section{Pedagogical approach}

It remains the case, however, that like the shorter podcasts, many longer podcasts were also constrained to a knowledge transmission pedagogy. This included the history podcasts noted above, for which historical stories were told in a flowing narrative. While several of the podcasters were analytical and insightful of their interpretations of history, there was minimal diversity of opinions available in single-author podcasts to model dialogic pedagogies. This is in contrast to several of the science podcasts whose dialogic approaches often involved backand-forth discourse over the merits of various ideas amongst panel participants. Thirdly, several language learning podcasts like Coffee Break Spanish aimed to be constructivist in their approaches through, for example, moments of pause to encourage listeners to construct their own sentences out of the grammar points presented. No real-time pedagogical moments 
of co-construction between students is possible with the affordances of podcasts; although it was noted during coding that some podcasts had associated forums (Show Time Spanish, Coffee Break Spanish) which might have involved co-construction of knowledge 'after the fact', but detailed exploration of associated forums was outside the scope of this study. This is a possible line for future research.

Based on the various pedagogical approaches identified, then, no one approach emerged as dominant. However, promising signs indicate that subject-specific trends may emerge from future studies, whereby history podcasts in this corpus were more often than not single-author and transmissive; and science podcasts were more often than not multi-author and dialogic.

Style

There was tendency across the corpus for podcasts to be informal, affirming consensus in the podcasting literature (Fothergill, 2008). In particular, podcasts that were not scripted such as the panel discussions in many of the science podcasts (Star Cast, Science Friday, Probably Science) were heavy on humour. Indeed, the podcast Star Cast involved professional comedians alongside notable scientists to deliver educational content in entertaining ways. A minority (7 of 20) of podcasts, however, were coded during analysis as 'semi-formal' (see: Coffee Break Spanish, British History Podcast, Grammar Girl), and these tended to remain scripted, with occasional divergences to informality, particularly in transition between segments or at the introduction and conclusion sections. The podcasts that were designated semi-formal also tended to have more traditional authoritative teacher figures who directed the conversations and at times kept other characters 'in line' (see Show Time Spanish as an archetypal example).

\section{Series Structure}


There was a mix of linear and non-linear podcasts in the corpus. Non-linear podcasts tended to focus on current affairs (Science Friday, Probably Science, You are not so Smart), content selected by listeners (Grammar Girl, History Chicks), or content selected by podcast creators (History Chicks, Daily French Pod). Science podcasts tended to be non-linear, while there was a mix of linear and non-linear series structures across the corpus of language learning and history podcasts. Affirming extant literature on good design practice (Kidd, 2011), signposting was common across both linear and non-linear podcasts. Dan Carlin's Revolutions and Hardcore History podcasts, for example, each involved linear historical narratives that crossed over entire series, requiring signposting at the beginning of episodes to re-orient listeners as to where they were up to in the course. Similarly, the non-linear History Chicks podcast also sustained significant signposting, often in order to direct listeners to related podcasts within the series when characters such as members of the House of Tudor recurred across several episodes.

\section{Fit with Other Teaching Materials}

It has been noted already that the majority of podcasts emerging from academic institutions are substitutional or supplemental (Hew, 2009). The non-institutional podcasts that are the subject of this study have challenged this orthodoxy to the extent that all podcasts involved unique content delivery and were the central modes of delivering content to learners. All podcasts also use associated websites to provide additional learning materials which are 'supplementary' to the podcast, as shown in Table 2.

[Table 2 near here - see appendix]

All four of the language-learning podcasts in the corpus had associated worksheets for learners to complement their listening. Concomitantly, the show notes on 17 of the 20 podcasts acted as a resource for learners to continue their studies of what was presented in the 
shows. The Naked Scientists is one such podcast that provides show notes on their website for each episode. Each podcast is accompanied with a 'Related content' section that links listeners to further podcasts from their extensive archives. Furthermore, tabs on the web pages on which the podcast is hosted takes listeners to 'Articles', 'Science news', and 'Interviews' that direct podcast listeners to content that can further promote learning about presented content.

Similarly, the Grammar Girl podcasts frequently refer listeners to an associated website which offers 'articles based on the podcast episodes' (http://www.quickanddirtytips.com), e-newsletters and audiobooks. Instructive here is that the extra content is based on the podcasts, and not the other way around: unlike the dominant theme within education studies literature (Hew \& Cheung, 2013), podcasting tends to be a central rather than 'supplementary' feature of the learning experience.

\section{Discussion}

The findings of this study have both supported and challenged extant literature. To summarise, humour and informality have been evident in many of the podcasts in this study, affirming extant literature (Fothergill, 2008). Signposting also remained common (Kidd, 2011). However, many of these highly-downloaded podcasts were significantly longer than conventional wisdom suggests as good practice, particularly amongst science and history themed podcasts. Shorter podcasts appeared limited to a transmissive pedagogical approach and fostering lower-level cognitive skills.

The podcasts in this study function as models for moving podcasting to the centre of the learning experience, integrating podcasting technology into curricula rather than using it as an addendum to learning that takes place elsewhere. All podcasts were considered to be unique content matter with associated learning materials being supplementary to the podcast; 
something called for in the literature (Abdous et al., 2012), but not consistently achieved in institutional contexts. The primary way in which this is done, is the provision of materials that support and supplement the learning that takes place in the podcast, such as help sheets, supporting websites, and worksheets, rather than relying on podcasts as supplements to the 'main' learning taking place elsewhere.

A key limitation of this study was its constrained scope; and consequently, I have been careful not to suggest that the findings are generalizable beyond the study's corpus. Indeed, one of the key takeaways from this study is that universalizing about podcast design principles is unwise. The diversity of variables in podcast design evident across the corpus of highly-downloaded podcasts reveals how 'good practice' should be considered a contextual term when it comes to podcast design. There have, however, been some positive signs that an element of contextualization of good practice lies in the subject-matter of podcasts, to the extent that there are potentially fruitful avenues to exploring 'fitting' practices for particular subject areas, rather than universalising good practice in education podcasting across all subjects and contexts. Some examples of subject-specific practices include the extensive use of storytelling in many of the history podcasts, and panel discussion in science-related content. Further research could therefore focus on podcasts from specific subject areas to identify how podcasters embrace certain podcast designs for subject-specific needs.

Indeed, there are many more avenues for further analysis of education podcast designs. One concern is whether the podcast designs in this study, which targeted independent rather than institutional learning, would transfer over to more structured learning environments. It would be logical, for example, that academic podcasts integrated into a unit of work would likely benefit from a linear series structure in order to assist students as they progress through course materials, which may not fit with many of the non-linear formats of some current affairs based podcasts in this study. 
Education podcasting, although in use for over a decade in tertiary institutions, will likely continue to evolve in response to the needs of learners. In light of this, the successful education podcasts that exist for download on podcast aggregation sites can introduce new insights that are to date underemphasized in educational podcasting literature; and analysis of these podcasts can challenge emerging orthodoxies about how podcasting can be used in educational contexts including in regards to podcast length, pedagogical approaches, and the position of the podcast in the learning experience. Moving away from universalizing ideas about good podcast design, and the conventionalised notion of short, supplemental, and transmissive podcasts, may help to maximise the potential of education podcasts in institutional contexts and lead to new and unique learning opportunities. It is the hope that the findings of this study might shift discourse from an interest in universalizing ideas about 'good practice' in education podcast design, towards more nuanced discussion of design practices that fit within specific contexts. 


\section{References}

Abdous, M., Facer, R., \& Yen, C. (2012). Academic effectiveness of podcasting: a comparative study of integrated versus supplemental use of podcasting in second language classes. Computers and Education, 58, 43-52. doi: 10.1016/j.compedu.2011.08.021

Ames, K. (2016). Talk vs chat-based radio: a case for distinction. Radio Journal: International Studies in Broadcast \& Audio Media, 14(2), 177-191. doi: https://doi.org/10.1386/rjao.14.2.177_1

Bell, T., Cockburn, A., Wingkvist, A, \& Green, R. (2007, February). Podcasts as a supplement in tertiary education: an experiment with two computer science courses. Paper presented at the meeting of Mobile learning technologies and applications (MoLTA), Auckland.

Bower, M., Hedberg, J, \& Kuswara, A. (2010). A framework for Web 2.0 learning design. Educational Media International, 47(3), 177-198. doi: http://dx.doi.org/10.1080/09523987.2010.518811

Carvalho, A., Aguilar, C., Carvalho, C. \& Cabecinhas, R. (2009). Influence of podcasts characteristics on higher students' acceptance. In C. Bonk (ed.), Proceedings of world conference on e-learning in corporate, government, healthcare, and higher education 2008. (pp. 3625-3633) Chesapeake: Association for the Advancement of Computing in Education.

Chan, A., \& Lee, M. (2005). An MP3 a day keeps the worries away: exploring the use of podcasting to address preconceptions and alleviate pre-class anxiety amongst undergraduate information technology students. In D. Spennemann \& L. Burr (eds.), Good Practice in Practice: Proceedings of the Student Experience Conference (pp. 58-70). Wagga Wagga: Charles Sturt University.

Fernandez, V., Sallan, J., \& Simo, P. (2015). Past, present, and future of podcasting in higher education. In M. Li \& Y. Zhao (eds.), Exploring learning and teaching in higher education (pp. 305-330). Berlin: Springer.

Fernandez, L. (2007). I upload audio, therefore I teach. The Chronicle of Higher Education, 53(18). Retrieved from http://www.chronicle.com/article/I-Upload-Audio-Therefore$\mathrm{I} / 30812$

Fothergill, J. (2008). Podcasts and online learning. In G. Salmon \& P. Edirisingha (eds.), Podcasting for Learning in Universities (pp. 80-91). Berkshire: Open University Press.

Hadjianastasis, M., \& Nightingale, K. (2016). Podcasting in the STEM disciplines: the implications of supplementary lecture recording and 'lecture flipping'. FEMS microbiology letters, 363(4). doi: https://doi.org/10.1093/femsle/fnw006

Hew, K., \& Cheung, W. (2013). Use of Web 2.0 technologies in K-12 and higher education: the search for evidence-based practice. Educational Research Review, 9, 47-64. doi: http://dx.doi.org/10.1016/j.edurev.2012.08.001 
Hew, K. (2009). Use of audio podcast in K-12 and higher education: a review of research topics and methodologies. Educational Technology Research and Development, 57(3), 333-357. doi: 10.1007/s11423-008-9108-3

Kidd, W. (2011). Utilising podcasts for learning and teaching: a review and ways forward for e-learning cultures. Management in Education 26 (2): 52-57. doi: $10.1177 / 0892020612438031$

Larkin, H. (2010). But they won't come to lectures: the impact of audio recorded lectures on student experience and attendance. Australasian Journal of Educational Technology 26(2): 238-249. doi: http://dx.doi.org/10.14742/ajet.1093

Lee, M., \& Chan, A. (2007). Reducing the effects of isolation and promoting inclusivity for distance learners through podcasting. Turkish Online Journal of Distance Education, 8(1), 85-105. Retrieved from http://files.eric.ed.gov/fulltext/ED494811.pdf

Lee, M., \& Tynan, B. (2008). Podcasts and distance learning. In G. Salmon \& P. Edirisingha (eds.), Podcasting for Learning in Universities (pp. 92-102). Berkshire: Open University Press.

Lindgren, M. (2016). Personal narrative journalism and podcasting. Radio Journal: International Studies in Broadcast \& Audio Media, 14(1), 23-41. doi: https://doi.org/10.1386/rjao.14.1.23_1

Lonn, S., \& Teasley, S. (2009). Podcasting in higher education: what are the implications for teaching and learning? The Internet and Higher Education, 12(2), 88-92. doi: http://dx.doi.org/10.1016/j.iheduc.2009.06.002

Nie, M., Armellini, A., Harrington, S., Barklamb, K., \& Randall, R. (2010). The role of podcasting in effective curriculum renewal. ALT-J, 18(2), 105-118. doi: http://dx.doi.org/10.1080/09687769.2010.492849

On Tam, C. (2012). The effectiveness of educational podcasts for teaching music and visual arts in higher education. Research in Learning Technology 20. doi: http://dx.doi.org/10.3402/rlt.v20i0.14919

Rosell-Aguilar, F. (2007). Top of the pods - In search of a podcasting 'podagogy' for language learning. Computer Assisted Language Learning, 20(5), 471-492. doi: http://dx.doi.org/10.1080/09588220701746047

Salmon, G., \& Nie, M. (2008). Doubling the life of iPods. In G. Salmon \& P. Edirisingha (eds.), Podcasting for Learning in Universities (pp. 1-12). Berkshire: Open University Press.

Seery, M. (2012). Podcasting: support and enrich chemistry education. Education in chEmistry, 49(2), 19. Retrieved from https://eic.rsc.org/

Walsh, S. (2004). Appendix: IPod, therefore I learn. In D. Clark \& S. Walsh (eds.) iPodlearning (pp. 23-29). Brighton: Epic Group. 
Table 1.

\begin{tabular}{|c|c|c|c|c|c|c|c|c|c|c|}
\hline 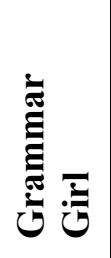 & 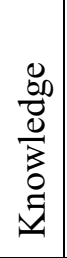 & 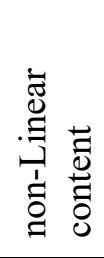 & 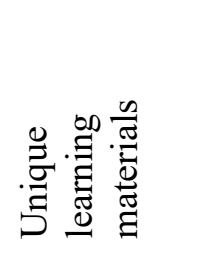 & 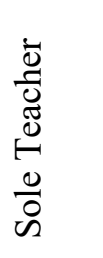 & 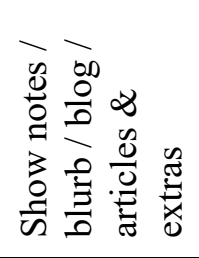 & 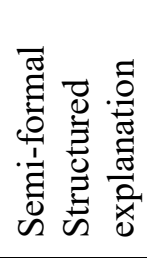 & 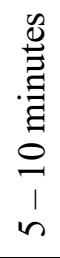 & 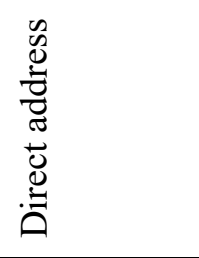 & 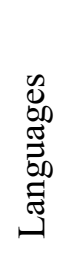 & 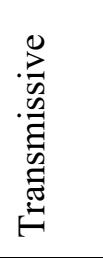 \\
\hline 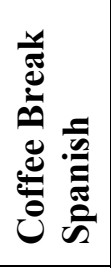 & 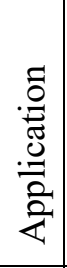 & 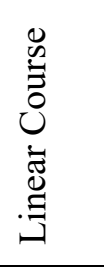 & 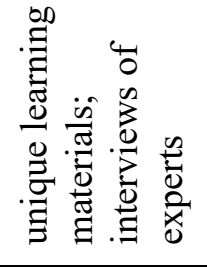 & 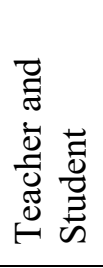 & 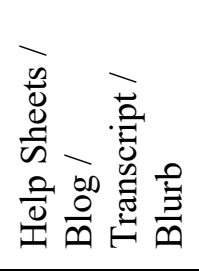 & 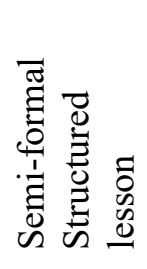 & 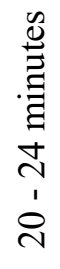 & 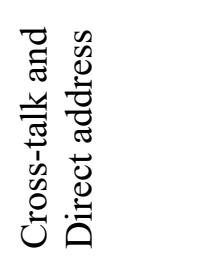 & 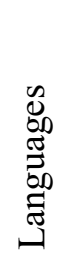 & 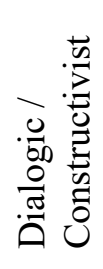 \\
\hline 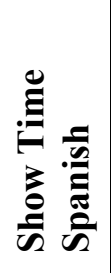 & 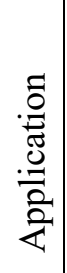 & 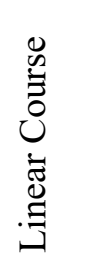 & 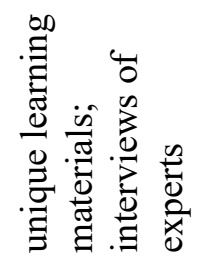 & 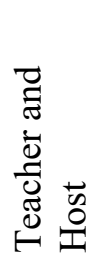 & 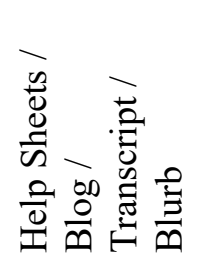 & 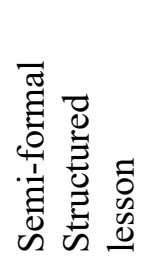 & 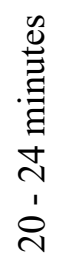 & 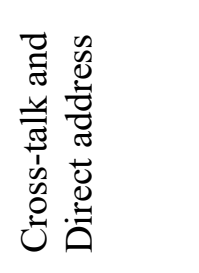 & 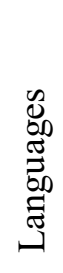 & 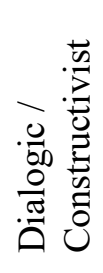 \\
\hline 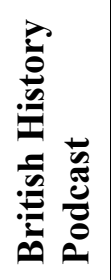 & $\begin{array}{l}\tilde{0} \\
\frac{0}{0} \\
\overline{0} \\
\overline{0} \\
\overline{0} \\
0 \\
0\end{array}$ & 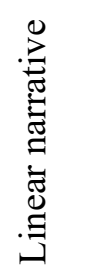 & 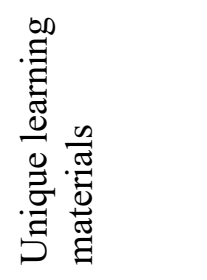 & $\begin{array}{l}\vec{y} \\
\stackrel{0}{1}\end{array}$ & 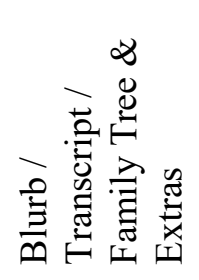 & 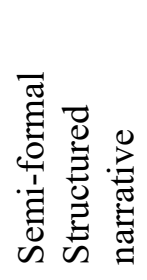 & 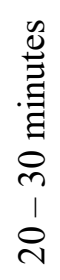 & 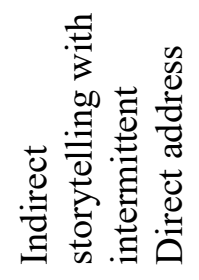 & $\begin{array}{l}\overrightarrow{0} \\
\stackrel{0}{0} \\
: 3\end{array}$ & 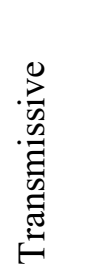 \\
\hline 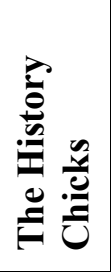 & $\begin{array}{l}\tilde{0} \\
\frac{0}{0} \\
\overline{0} \\
\overline{0} \\
\overline{0} \\
0 \\
0\end{array}$ & 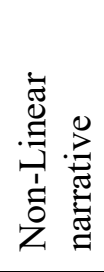 & 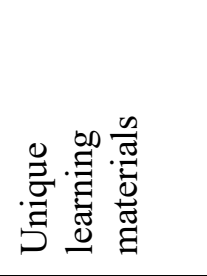 & $\begin{array}{l}\text { 号 } \\
\text { O } \\
\text { I }\end{array}$ & 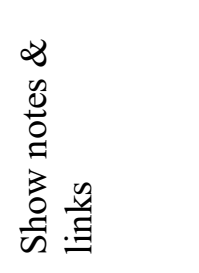 & 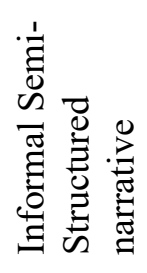 & 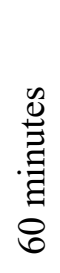 & 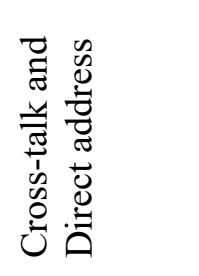 & $\begin{array}{l}\overrightarrow{0} \\
\stackrel{0}{0} \\
: 0\end{array}$ & 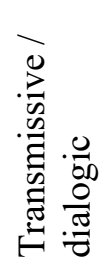 \\
\hline 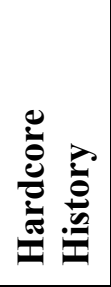 & 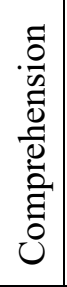 & 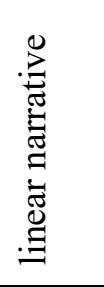 & 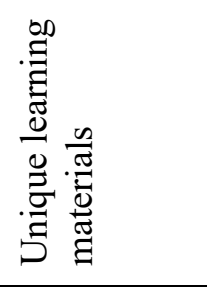 & $\begin{array}{l}\vec{y} \\
\stackrel{0}{1} \\
\text { 足 }\end{array}$ & 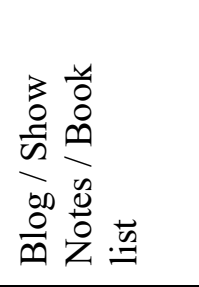 & 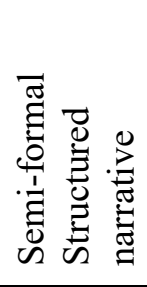 & 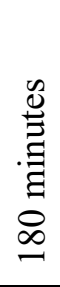 & 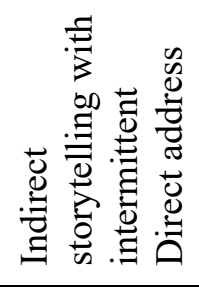 & $\begin{array}{l}\overrightarrow{0} \\
\stackrel{0}{0} \\
0 \\
0\end{array}$ & 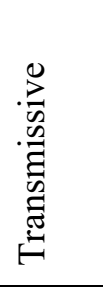 \\
\hline 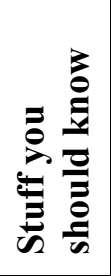 & 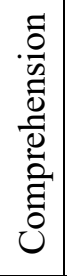 & 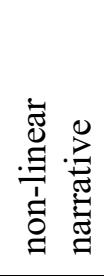 & 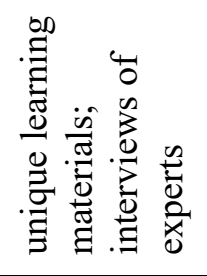 & $\begin{array}{l}\bar{\Phi} \\
\tilde{\Xi} \\
\tilde{\Xi}\end{array}$ & 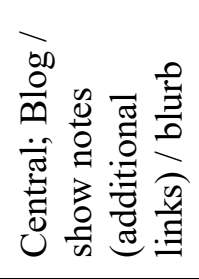 & 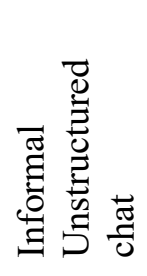 & 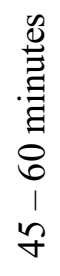 & 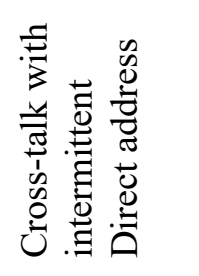 & 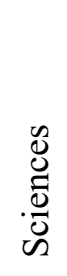 & $\begin{array}{l}.0 \\
\frac{0}{00} \\
\frac{0}{0 \pi} \\
.0\end{array}$ \\
\hline & 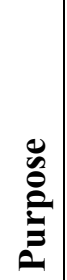 & 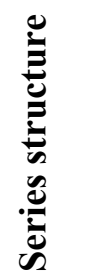 & $\stackrel{D}{\not}$ & 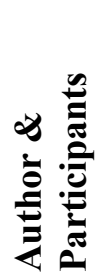 & 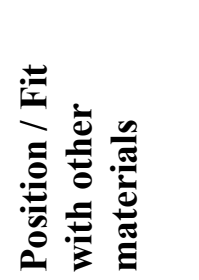 & $\sum_{\infty}^{\infty}$ & 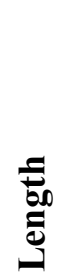 & 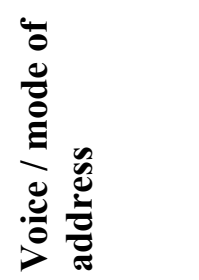 & 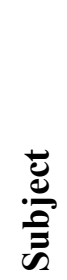 & \\
\hline
\end{tabular}




\begin{tabular}{|c|c|c|c|c|c|c|c|c|c|c|}
\hline 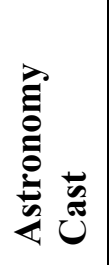 & 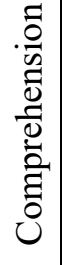 & 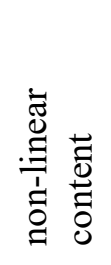 & 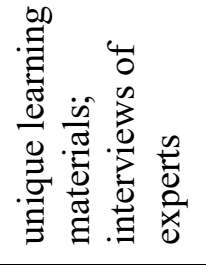 & $\begin{array}{l}\vec{y} \\
\text { 昰 }\end{array}$ & 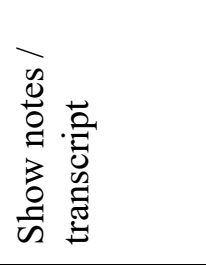 & 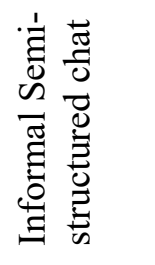 & 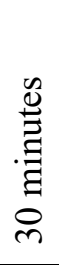 & 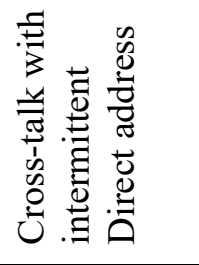 & 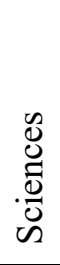 & 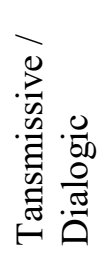 \\
\hline 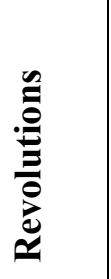 & 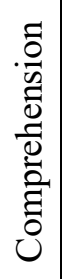 & 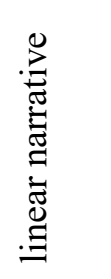 & 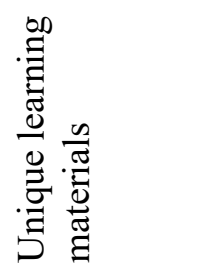 & $\begin{array}{l}\vec{y} \\
\stackrel{0}{1}\end{array}$ & 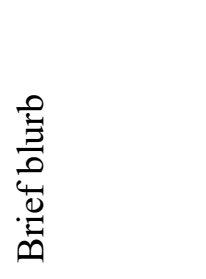 & 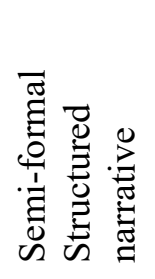 & 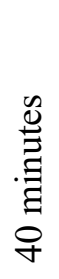 & 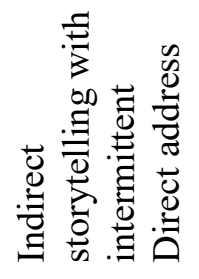 & 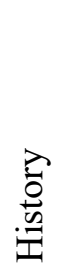 & 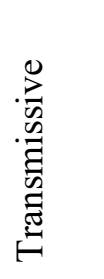 \\
\hline 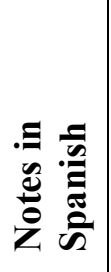 & 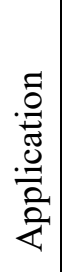 & 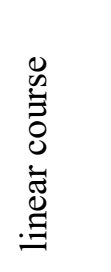 & 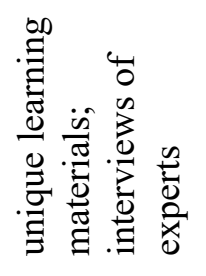 & 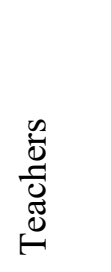 & 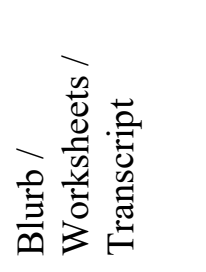 & 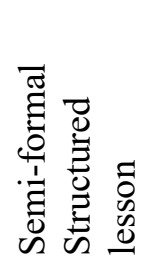 & $\begin{array}{l}\stackrel{0}{0} \\
\stackrel{\Xi}{\Xi} \\
\vdots \\
= \\
1 \\
0\end{array}$ & 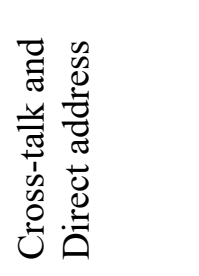 & 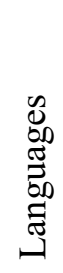 & 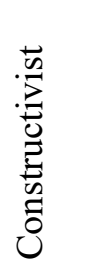 \\
\hline 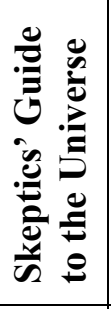 & 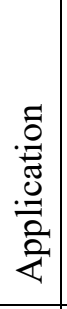 & 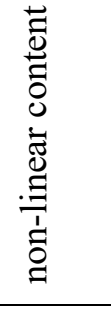 & 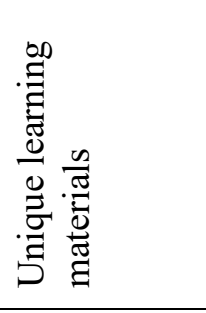 & $\begin{array}{l}\bar{\Xi} \\
\tilde{\Xi} \\
\approx\end{array}$ & 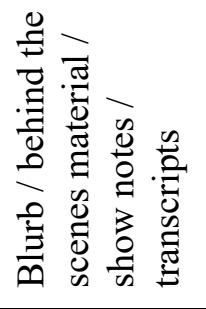 & 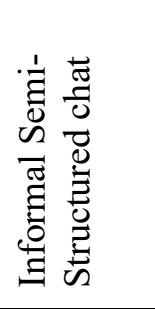 & $\begin{array}{l}\stackrel{0}{0} \\
\stackrel{\Xi}{\Xi} \\
\text { ! } \\
0 \\
0 \\
1 \\
0 \\
+\end{array}$ & 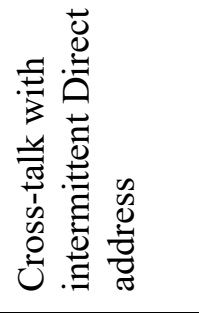 & 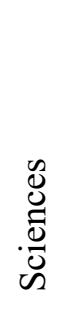 & 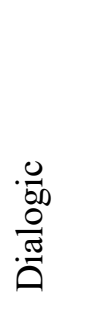 \\
\hline 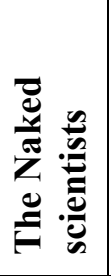 & 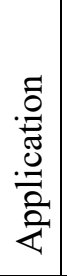 & 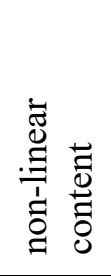 & 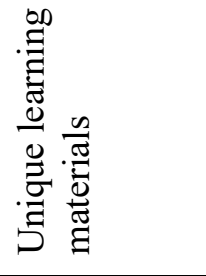 & $\begin{array}{l}\bar{\Xi} \\
\tilde{\Xi} \\
\text { ص. }\end{array}$ & 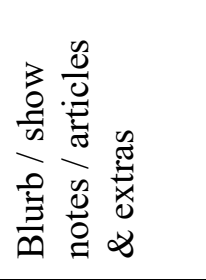 & 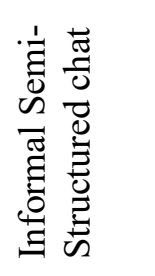 & 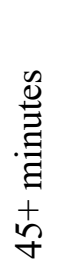 & 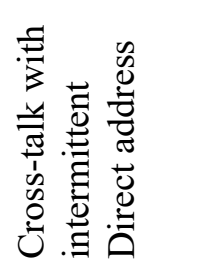 & 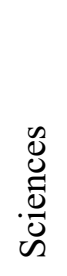 & 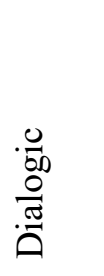 \\
\hline 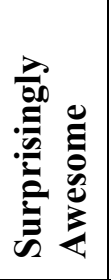 & 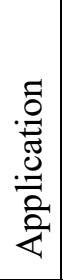 & 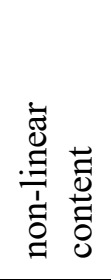 & 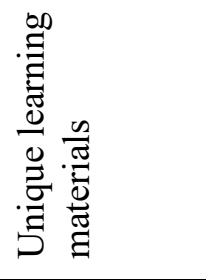 & $\begin{array}{l}\bar{\Phi} \\
\bar{\Xi} \\
\tilde{\sigma}\end{array}$ & 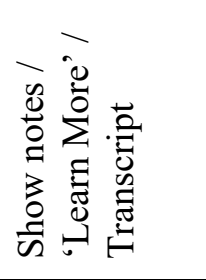 & 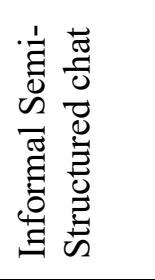 & 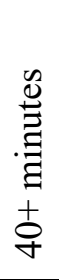 & 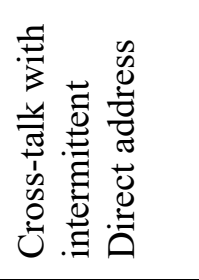 & 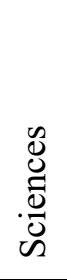 & $\begin{array}{l}\frac{0}{60} \\
\frac{0}{\sigma \pi} \\
\frac{\pi}{0}\end{array}$ \\
\hline 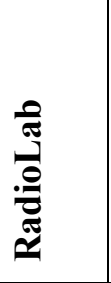 & 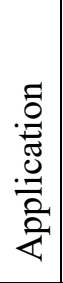 & 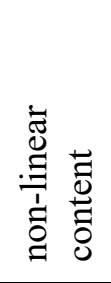 & 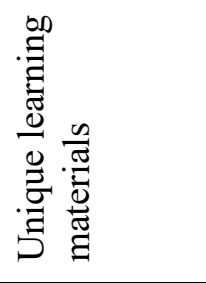 & $\begin{array}{l}\bar{\Phi} \\
\bar{\Xi} \\
0\end{array}$ & $\begin{array}{l}3 \\
0 \\
0 \\
0 \\
0 \\
0 \\
0 \\
0 \\
0 \\
0 \\
0 \\
0 \\
0\end{array}$ & 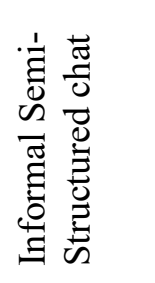 & 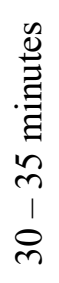 & 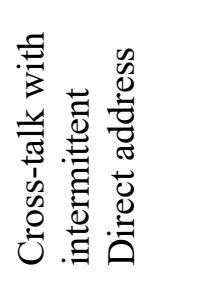 & 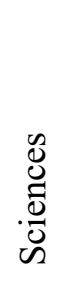 & $\begin{array}{l}\frac{0}{00} \\
\frac{0}{\pi} \\
\frac{\pi}{0}\end{array}$ \\
\hline & 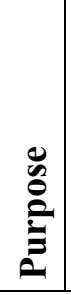 & 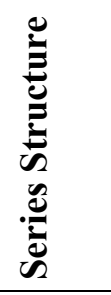 & $\sum_{i}^{0}$ & 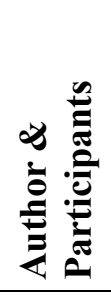 & 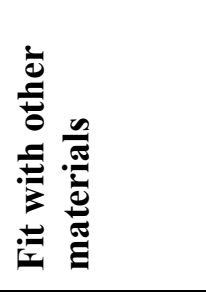 & $\frac{0}{\pi}$ & 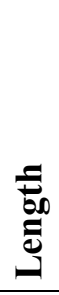 & 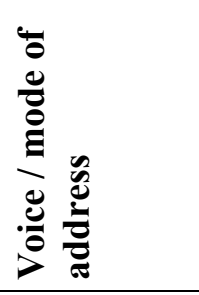 & 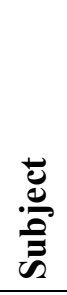 & \\
\hline
\end{tabular}




\begin{tabular}{|c|c|c|c|c|c|c|c|c|c|c|}
\hline 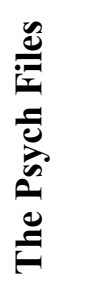 & 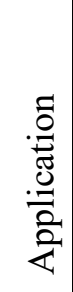 & 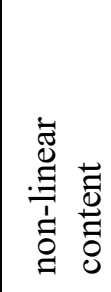 & 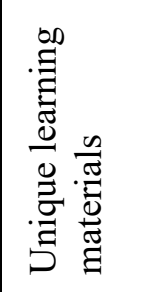 & $\begin{array}{l}\bar{\Xi} \\
\bar{\Xi} \\
\text { N }\end{array}$ & 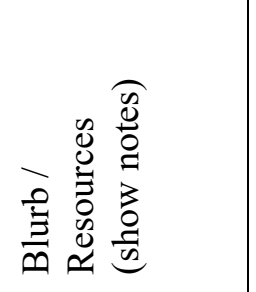 & 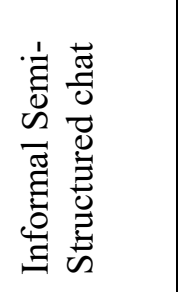 & 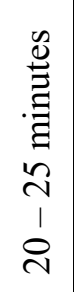 & 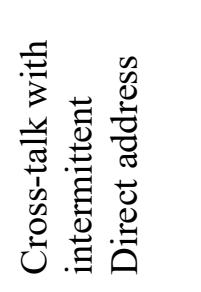 & $\begin{array}{l}\text { 命 } \\
\frac{0}{0} \\
0 \\
0 \\
0 \\
0 \\
0\end{array}$ & 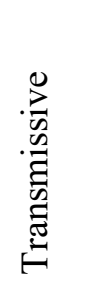 \\
\hline 离 & 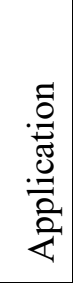 & 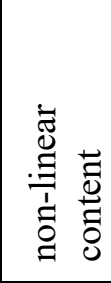 & 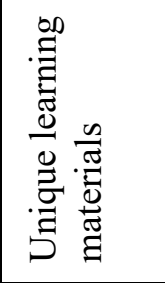 & $\begin{array}{l}n \\
0 \\
0 \\
0 \\
0 \\
\infty \\
0 \\
0 \\
0 \\
0 \\
0\end{array}$ & 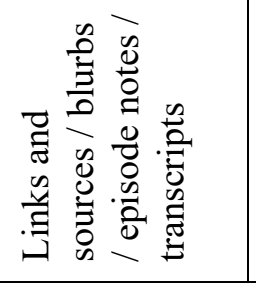 & 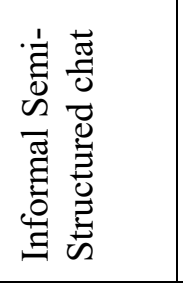 & 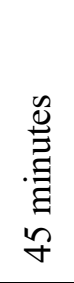 & 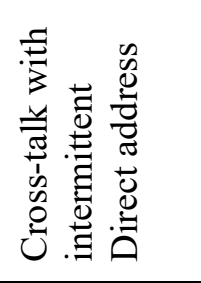 & 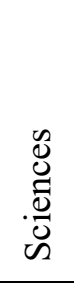 & $\begin{array}{l}.0 \\
.00 \\
\frac{0}{\sigma \pi} \\
. \bar{\theta}\end{array}$ \\
\hline 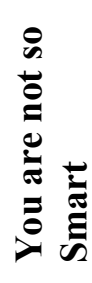 & 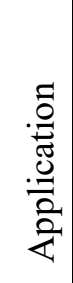 & 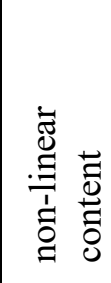 & 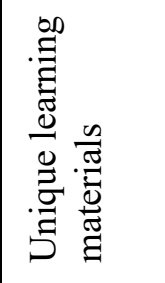 & 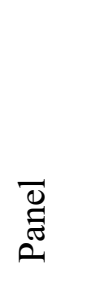 & 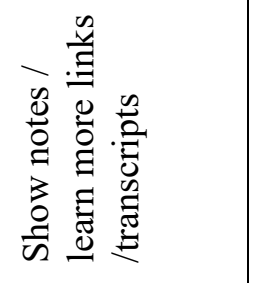 & 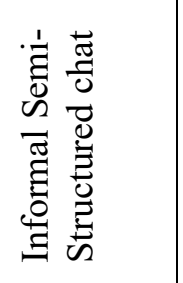 & 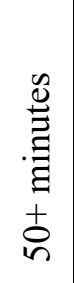 & 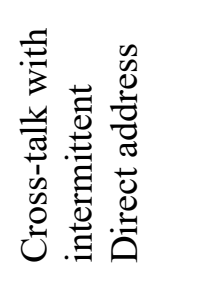 & 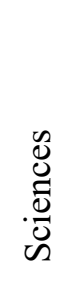 & $\begin{array}{l}.0 \\
.00 \\
\frac{0}{\sigma 0} \\
. \bar{\theta}\end{array}$ \\
\hline 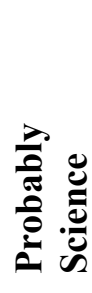 & 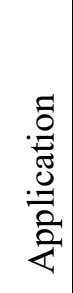 & 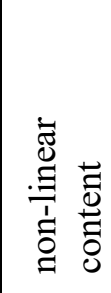 & 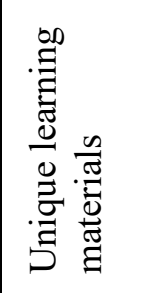 & $\begin{array}{l}\bar{\Xi} \\
\tilde{E} \\
\tilde{D}\end{array}$ & 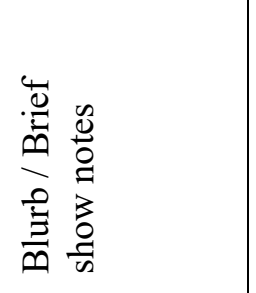 & 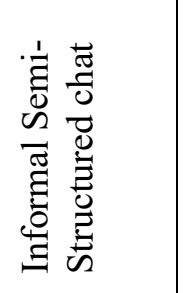 & 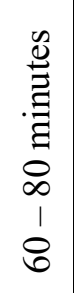 & 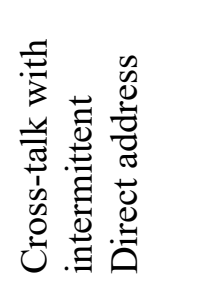 & 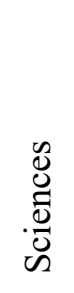 & 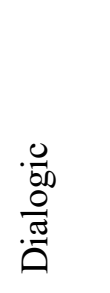 \\
\hline 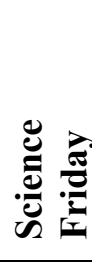 & 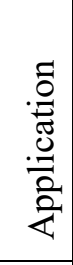 & 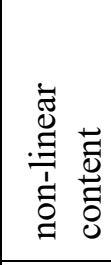 & 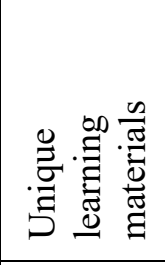 & $\begin{array}{l}\bar{\Xi} \\
\tilde{\Xi} \\
\tilde{E}\end{array}$ & 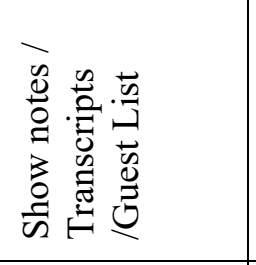 & 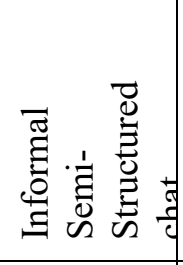 & $\begin{array}{l}\stackrel{9}{1} \\
1 \\
0 \\
-\end{array}$ & 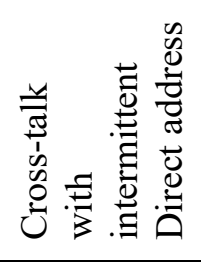 & 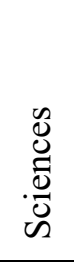 & 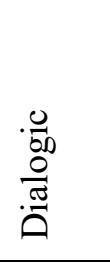 \\
\hline 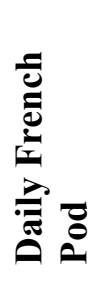 & $\begin{array}{l}8 \\
0 \\
0 \\
0 \\
0 \\
0 \\
0 \\
0\end{array}$ & 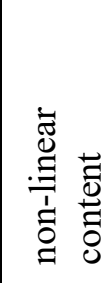 & 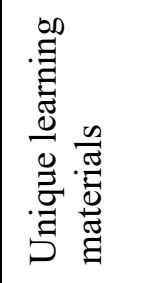 & $\begin{array}{l}\vec{y} \\
\stackrel{0}{1}\end{array}$ & 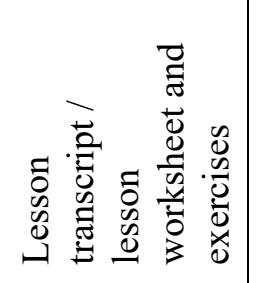 & 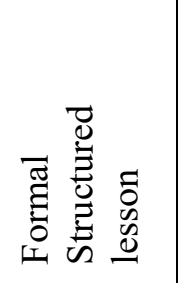 & 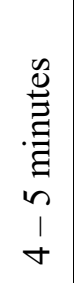 & 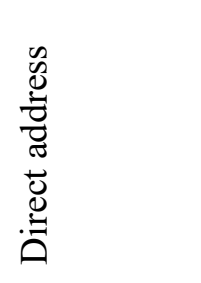 & 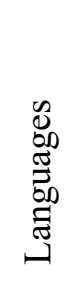 & 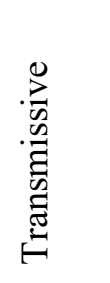 \\
\hline & 总 & 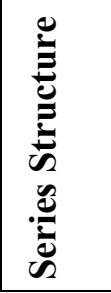 & $\overbrace{E}^{\circ}$ & 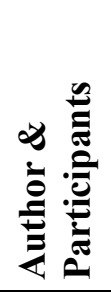 & 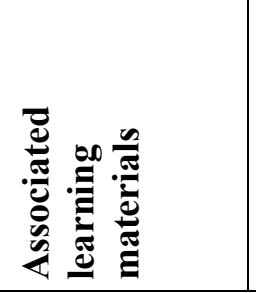 & $\stackrel{0}{D}$ & 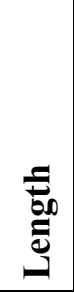 & 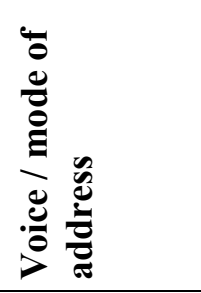 & & 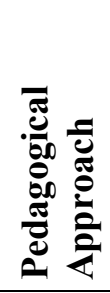 \\
\hline
\end{tabular}


Table 2.

\begin{tabular}{l|l} 
Supplemental Materials & Identified for
\end{tabular}

\begin{tabular}{l|l}
\hline Worksheets & 4 out of 20 podcasts \\
\hline Show Notes & 17 out of 20 podcasts \\
\hline Blogs \& Articles & 7 out of 20 podcasts \\
\hline Transcripts & 10 out of 20 podcasts
\end{tabular}

Table 2. Supplemental materials on podcast websites 